\title{
ENSINO DE ESPORTES POR MEIO DE JOGOS: DESENVOLVIMENTO E APLICAÇÕES
}

\author{
Renato Sampaio Sadi \\ Doutor em Educação e professor da FEF/UFG. \\ Janaína Cortês Costa \\ Especialista em Educação Física Escolar e professora da rede estadual de educação de Goiânia.
}

\section{Bárbara Torres Sacco}

Acadêmica (bolsista) do $4^{\circ}$ ano da FEF/UFG.

\section{Resumo}

O desenvolvimento da Pedagogia do Esporte no Brasil é tratado, neste texto, a partir da discussão do ensino de esporte por meio de jogos. O referencial teórico utilizado é a abordagem americana de Mitchell, Oslin e Griffin (2003). São apresentados procedimentos pedagógicos e metodológicos relativos a jogos de invasão e perspectivas de trabalho aos professores de Educação Física.

Palavras-chave: esporte - pedagogia- educação física.

\section{Introdução}

ensino de esportes para crianças dentro da Pedagogia do Esporte ainda é pouco explorado no Brasil. Este texto apresenta uma síntese da proposta americana relativa aos denominados jogos de invasão.

A compreensão do esporte, em um sentido amplo, tem a abrangência do jogo como categoria fundante. ${ }^{1} \mathrm{O}$ esporte é um produto cultural que surge do jogo e, somente quando institucionalizado, é assim intitulado. Desta forma, todo esporte se origina de um jogo e, dessa perspectiva, é fácil compreender a utilização dos jogos como elementos metodológicos para o ensino do esporte.

\footnotetext{
1 Desenvolvemos o conceito jogo a partir da perspectiva de compreendê-lo dentro de um sistema complexo e de totalidade, em que seu ambiente (contexto) determinará o que é jogo e não-jogo, evidenciando a predominância da subjetividade em detrimento da objetividade (o estado de jogo) cf. Scaglia (2005).
}

$\mathrm{Na}$ perspectiva de ensino aqui adotada, ao tratar de crianças e adolescentes, torna-se necessária a abrangência de procedimentos que vão dos mais simples aos mais complexos, via de regra, da idéia mais geral ao fazer/executar específico, sempre contemplando múltiplas dimensões.

O esporte, como herdeiro do jogo, possui dois pontos relevantes para o ensino/aprendizagem: a estruturação de jogos e a promoção/ substituição das tradicionais modalidades esportivas por atividades em jogos esportivos.

A classificação da abordagem americana envolve quatro categorias de jogos: jogos de invasão, jogos de rede/parede, jogos de rebatida/campo e jogos de alvo. Os jogos de invasão abarcam elementos que trabalham a subcategoria decisão, tomando como exemplo as expressões: "para quem devo passar a bola", "quando devo passar ou driblar", "quando e como atacar", "quando e como defender" meu campo do adversário. Nos jogos de rede/parede as decisões importantes estão baseadas nos seus limites físicos, como força, resistência, 
agilidade e no posicionamento do adversário. Os jogos de rebatida/campo e os jogos de alvo não são difundidos entre professores de Educação Física, apesar de serem essenciais para desenvolver técnicas variadas de rebatida e lançamento. Neste artigo, a ênfase da análise de ensino de esporte por meio de jogos será dada aos jogos de invasão, pela própria familiaridade entre os professores.

O conhecimento em esportes deve inicialmente ser adaptado/ajustado às características das crianças - jogadores, que podem facilmente reproduzir diferentes jogos de invasão, retendo um grau de conhecimento dos processos ou técnicas de jogo, transferidos de um para outro - o que justifica a utilização de espaços reduzidos. Também chamados de mini-jogos, estas práticas possibilitam a apreensão da similaridade presente nos jogos de invasão, quando as crianças são capazes de conservar os conhecimentos e táticas dos jogos para a realização de outros jogos.

Outros elementos constitutivos da referida metodologia dizem respeito às dimensões de quadras, diminuição do número de jogadores, peso de bolas, tamanhos/ alturas de equipamentos e tempos de jogo.

O conceito de jogos esportivos substitui o termo modalidades, pelo sentido plural que os esportes carregam em sua densidade qualitativamente diferente das modalidades esportivas que enfatizam uma conotação no singular. Em outras palavras, o universo de práticas esportivas é constituído por jogos de diferentes famílias, formadoras de vários tipos de comunidades. Por essa possibilidade de totalidade, o esporte, pensado individualmente, se apresenta fechado e resistente às mudanças.

O desenvolvimento de materiais educativos para tal temática requer que o professor identifique, em primeiro lugar, os problemas táticos. ${ }^{2}$ Esses, por sua vez, devem ser obje-

2 Tática é compreendida como a necessidade de resolução de problemas pelos jogadores no interior do jogo. As diferenças centrais entre Tática e Estratégia tivados em jogos elementares, ensinados em seqüências apropriadas relacionadas com essa problemática. Classificados mediante as questões táticas e a solução desses problemas, o ensino dos jogos se constitui por uma tríade interativa, como:

1) decisões a serem realizadas;

2) movimento sem bola;

3) seleção e execução de habilidades com bola.

$\mathrm{Na}$ seqüência, dentro da particularidade dos jogos esportivos, comentamos as sete observações formuladas por Mitchell, Oslin e Griffin (2003) para a efetivação dos procedimentos pedagógicos:

1) "O ensino de táticas é um esquema de resolução de problemas para o ensino de jogos que improvisa conhecimento de jogos e esportes e, é motivante, porque os alunos sentem prazer na realização dos jogos."

1) Comentário: Ensinar táticas de forma critica e criativa envolve complexificar questóes para os alunos simplificarem. A prática de babilidades dentro do ensino de táticas torna este ensino agradável, motivante e, sobretudo, eficaz.

2) "O esquema de ensino de táticas nos jogos classifica-os de acordo com as similaridades táticas, como: jogos de invasão, jogos de rede/parede, jogos de rebatida/campo e jogos de alvo."

2) Comentário: Diversos jogos podem implicar em educação esportiva de qualidade, entretanto, cabe aos professores a seleção e classificação para fins de didática, de exposição e experimentação.

3) Nas séries iniciais do ensino fundamental, o ensino dos jogos deve ser enquadrado na classificação citada, para que os alunos possam compreender as semelhanças.

se situam nos objetivos destas ações. Cf. Garganta (2006). Enquanto Tática é uma ação provisória, Estratégia se relaciona com a idéia de um projeto mais duradouro. 
3) Comentário: O periodo das séries iniciais do ensino fundamental é bastante rico para o ensino de esporte por meio de jogos, ainda pouco explorado pelos professores nesta fase, talvez pelo receio, pela novidade ou por falta de oportunidade.

4) Dentro de cada uma das categorias, os jogos podem ser divididos em problemas táticos, que passam a ser o foco do plano de ensino.

4) Comentário: Categorizar jogos e organizar problemas táticos passa então a ser uma tarefa fundamental do modelo do TGFU, além de se apresentar como uma interessante perspectiva de trabalho para os professores.

5) As crianças aprendem a resolver problemas táticos durante o jogo e a competição, tomando as seguintes decisões: utilizam movimentos quando estão sem a posse de bola e habilidades quando estão com a posse de bola.

5) Comentário: Torna-se fundamental, neste modelo, a diretividade do professor no tocante ao pensamento, à cognição, à compreensão. Assim, após o jogo, uma reflexão do que ocorreu na realidade deste jogo.

6) Após identificar os problemas táticos e suas possíveis soluções, a aprendizagem destas soluções pode ser progressivamente seqüenciada, partindo das questões mais simples em direção às mais complexas. Em níveis mais elevados de desenvolvimento, o professor pode planejar o ensino de jogos envolvendo uma maior complexidade tática de problemas e soluções.

6) Comentário: Seqüenciar e dosar conteúdos ésempre uma ferramenta que pode qualificaro currículo de Educação Física e Esporte. A questão precisa ser tratada no âmbito dos problemas táticos, que pressupóe um determinado conhecimento das séries, turmas, diversidades, entre outras.

7) Os esquemas de aulas que ensinam táticas nos jogos utilizam o seguinte caminho metodológico: a) A aula começa com um jogo que requer dos alunos a resolução de problemas táticos. Os alunos devem pensar o que precisam fazer para resolver o(s) problema(s) do jogo. Perguntas e respostas direcionam os alunos a identificar possíveis soluções (envolvendo movimentos e habilidades) para problemas táticos.

b) Os alunos praticam assim, os movimentos e habilidades requeridos para resolver os problemas táticos. De forma apropriada, tarefas e planos podem ser utilizados.

c) A aula termina com um segundo jogo, no qual os alunos aplicam as novas habilidades e movimentos apreendidos.

d) A compreensão e a solução dos problemas integram uma avaliação verbal que pode ser reforçada por discussões e votações.

7) Comentário: Aulas organizadas e conteúdos distribuidos são questôes fundamentais para a qualidade da Educação Física e Esporte nas escolas. Além disso, aulas produtivas implicam em dados a serem avaliados, isto é, a avaliação acaba sendo uma motivação para aprendizagem e novos processos de ensino.

\section{Procedimentos metodológicos}

Os procedimentos metodológicos para crianças e adolescentes jogarem em espaços pequenos (modificados e jogos independentes) dependem, da realidade e criatividade ${ }^{3}$ do professor. Particularmente, crianças pequenas precisam aprender a estrutura de regras e respeitar o jogo nas suas delimitações, isto é, nas linhas demarcatórias da quadra ou campo. Alunos do ensino fundamental $\left(6^{\circ}\right.$ ao $9^{\circ}$ ano) devem revelar suas habilidades em duas regras simples:

1) Quando sua bola atravessa um outro jogo aguardam em seu espaço para que a bola retorne (e atravessam por fora dos limites deste espaço, se necessário).

Criar é dar forma a algo novo, relacionar fenômenos de modo novo e compreendê-los em novos termos. $\mathrm{O}$ ato criador ou re-criador envolve a capacidade de compreender, relacionar, ordenar, configurar e significar. 
2) Quando uma bola de outro jogo atravessa o seu ambiente, eles param o seu jogo e devolvem a bola pertencente ao outro grupo (ou para a linha mais próxima do outro jogo).

Embora possa parecer simples, tais regras precisam ser ensinadas e reforçadas nos estágios elementares, no ensino de jogos, quando vários jogos estão sendo desenvolvidos. As crianças devem ser capazes de ter autocontrole quando sua bola ultrapassa os limites estabelecidos do seu jogo e, portanto, aguardar. Ao mesmo tempo, devem ser capazes de resistir à tentação de chutar ou jogar a bola que vem de outro jogo/campo. $\mathrm{O}$ ensino e o reforço destas regras auxiliam o processo pedagógico para que a criança tenha ciência de seus limites.

$\mathrm{Na}$ figura 1, o ginásio/quadra é dividido em quatro espaços para o ensino de jogos de invasão, numerados em seqüência 1, 2, 3 e 4 . O jogo é conduzido pela largura do ginásio, de tal forma que cada espaço é mais comprido que a largura, e as equipes (que permanecem as mesmas durante uma unidade de aulas) são permanentemente designadas para um determinado espaço, ou seja, ao entrar no ginásio/quadra e realizar as atividades de aquecimento e alongamento, já identificam o seu espaço. Esta organização facilita o início da aula com os alunos conhecendo o lugar onde devem ocupar. Dessa forma, realizam as atividades de aquecimento e alongamento independentemente. A chamada não é necessária nesse nível, mas pode ser feita no momento de aquecimento (alongamento). $\mathrm{O}$ aluno do ensino fundamental ( $6^{\circ}$ ao $9^{\circ}$ ano) pode atuar de forma independente, se organizado para tal. Os professores podem ensinar rotinas, regras, procedimentos de aquecimento e alongamento e outros aspectos de supervisão da mesma forma que podem ensinar outros conteúdos. Criar oportunidades de rotinas práticas para os alunos e oferecer-lhes apropriados retornos e elogios para implementação de êxito são também tarefas dos professores.

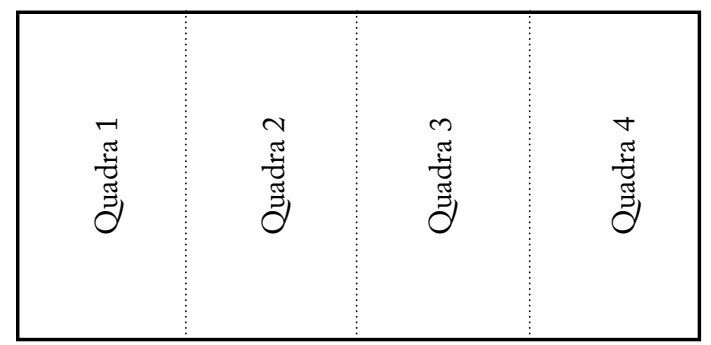

Figura 1 - Quadras ou campos (áreas para jogos de invasão)

Fonte: Mitchell, Oslin e Griffin (1997).

A figura 2 ilustra algumas possibilidades para jogos de rede. Na parte $\mathrm{A}$, o ginásio/quadra é dividido em duas partes com um número igual de espaços (6) em cada metade, totalizando doze pequenos espaços. As redes são estendidas em cada metade do ginásio, resultando áreas múltiplas para os jogos de rede/parede. Observe que nos estágios elementares os professores decidem como irão atuar sem as redes (talvez usando cones, cordas ou linhas) sobre as quais a bola deve cruzar. Isso possibilita o domínio do espaço para crianças. A parte B mostra as redes na largura do ginásio, criando espaços múltiplos, neste caso, em quatro divisões.

As aulas de Educação Física, como tantas outras, passam por rotinas, sendo consideradas formas constantes de se iniciar, desenvolver e encerrar o trabalho de ensino/aprendizagem. As rotinas interferem diretamente na otimização do tempo da aula de Educação Física. Muitas aulas iniciam com alunos sentados em pequenos grupos ou em círculo, de forma que o professor possa explicar o transcorrer das atividades e distribuir o material a ser utilizado. Rotinas que permitem um início de aula mais ativo, no qual os alunos possam entrar imediatamente na prática e organizar seu próprio material, são melhores do que as rotinas tradicionais a exemplo das que iniciam com a chamada presencial.

Consideremos uma classe de terceiro ano do ensino fundamental, tendo cerca de vinte e quatro alunos, todos envolvidos em jogos de 

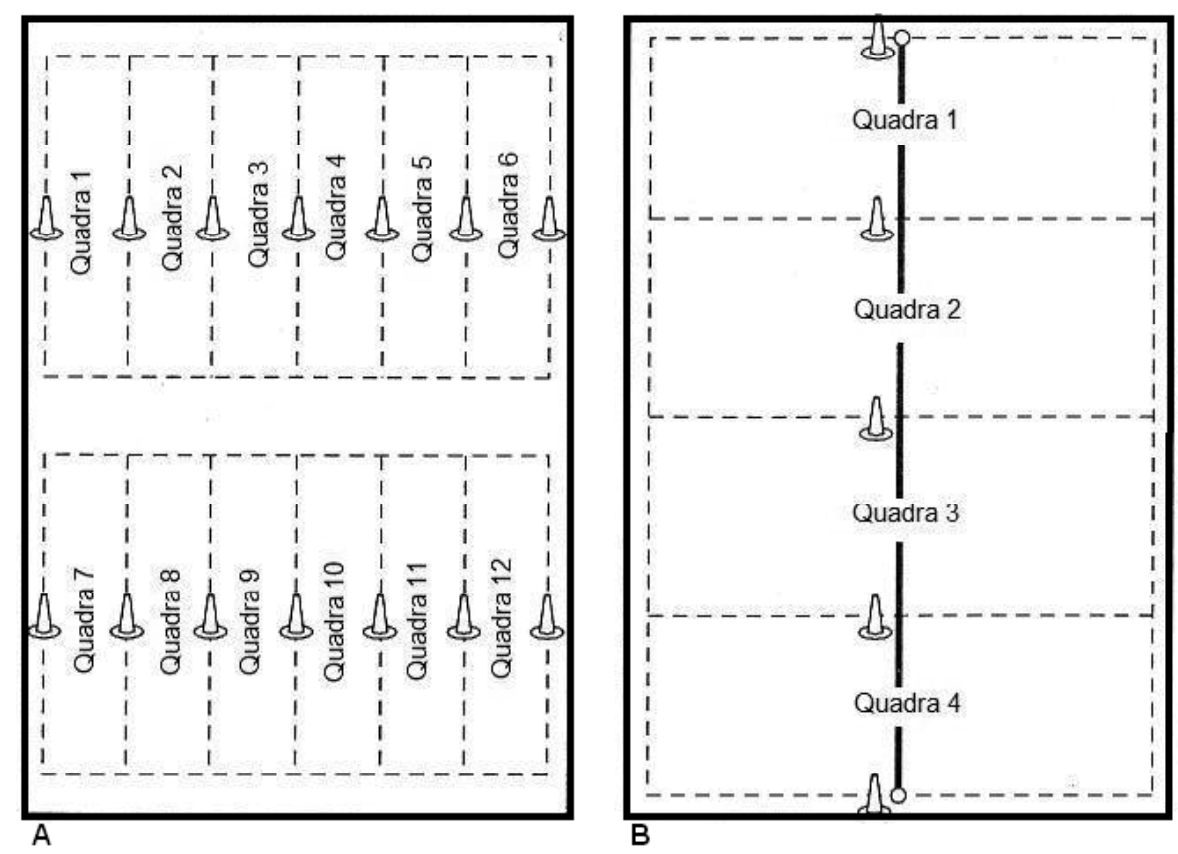

Figura 2 - (A) Divisão do ginásio para jogos de rede e (B) Arranjo da rede longitudinal

Fonte: Mitchell, Oslin e Griffin (1997).

rede, nos quais eles estão aprendendo táticas, habilidades e movimentos de um jogo de rede adaptado, numa determinada área. Sua preocupação reside numa simples troca de bola (passe e recepção por sobre uma linha ou talvez por um espaço no chão). A rede não é o foco do jogo na fase inicial, mas o desenvolvimento dos aspectos táticos, sem a preocupação de se ultrapassar a altura da rede. Pode-se também criar diversas variedades como o utilizar de uma obrigatoriedade de ação: "de um pingo" (exemplo: a bola deve pingar uma vez na quadra oposta à rede).

A primeira tarefa do professor envolve a organização de doze áreas de jogo e o início dos jogos o mais rápido possível. Pelo fato de não haver tempo para o professor organizar tais áreas, ele precisará de um sistema simples para que os alunos possam seguir suas rotinas dentro de suas próprias áreas. Utilizando demarcações de linhas na área de jogo (apresentadas na figura $2 \mathrm{~A}$ ), os alunos podem entrar na aula, organizando seu espaço, seu grupo, os cones, etc.

Há uma grande importância na utilização dos pequenos espaços de demarcação colorida para guiar os alunos na colocação dos cones em posição correta; os espaços serão completados independentemente dos jogadores, ao passo que os adversários podem localizar a bola que será utilizada. O jogo pode começar imediatamente após os espaços serem organizados, para que o tempo de aula seja bem aproveitado.

Durante as fases iniciais de aprendizagem, os jogos apresentam paradas naturais, de tal forma que os alunos precisam aprender como iniciar e re-iniciar o jogo quando houver uma parada (como uma bola indo para fora da quadra, por exemplo). Os alunos com mais experiência sabem que, quando uma equipe causa a saída da bola num jogo de invasão, por exemplo, o jogo é reiniciado pela linha lateral pela outra equipe. Este conceito 
deverá ser tentado por alunos iniciantes e freqüentemente relembrado até que a regra seja entendida. A priori, é melhor adaptar regras de re-início para que os alunos se familiarizem com a regra de forma que o jogo pode ser reiniciado sem que a bola tenha saído novamente. $\mathrm{O}$ professor pode estipular que um defensor deva estar a pelo menos um braço de distância do jogador adversário de forma que facilite o retorno da bola ao jogo ou pode usar a própria regra se achar necessário.

Em um jogo como o futebol, no qual a bola deve ser controlada com os pés, faz-se necessário que o aluno efetue um chute direto que possibilita o controle do jogador que recebe a bola; opções de re-início após um gol podem variar entre o re-início no meio do campo (como no futebol) ou o re-início na linha de fundo (como no basquetebol); a vantagem de utilizar o re-início da linha de fundo em todos os jogos de invasão é a economia de tempo; as crianças aprenderão a reiniciar mais rapidamente e farão uma melhor transição da defesa para o ataque antes que a equipe adversária se recomponha, o que poderia acontecer se a equipe reiniciasse no centro da quadra/campo. A escolha será do professor e dependerá das características e preferências dos alunos.

$\mathrm{Na}$ mesma direção, as adequações são interessantes para auxiliar em re-inícios de jogos de rede. Podemos enumerar algumas delas: primeiramente, em fases iniciais de aprendizagem, qualquer início e re-início pode muito bem ser feito por meio de sorteio, isso implica em uma facilidade para o aluno que irá recepcionar a bola e, portanto, uma maior probabilidade de rally (maior tempo de permanência no ar). Em segundo lugar, o saque deve ser alternado para que um só jogador não domine (ou fortaleça) o jogo neste fundamento. Terceiro, em jogos cujas regras, a pontuação é feita na vantagem do serviço, como no badminton (ou jogos modificados), por exemplo, um sistema de disputa da jogada deve ser utilizado com pontos a serem marcados (no serviço) por ambas as equipes. Mais uma vez tais regras proporcionam maior oportunidade de pontuação para iniciantes.

\section{Estrutura dos jogos de invasão}

Para o ensino de jogos de invasão, os jogos de $2 \times 2$ (dois contra dois) ou $3 \times 3$ (três contra três) são formas que favorecem o ensino aos alunos que estão iniciando. Deve-se ficar atento que o jogo $3 \times 3$ é mais complexo que o $2 \times 2$ por causa do terceiro jogador, no qual cada equipe possui uma opção adicional de passe. A escolha do jogo (2x2 ou $3 \times 3)$ pode também ser determinada pelo número de alunos na sala, tamanho da quadra e equipamento disponível. Sem considerar o tamanho da equipe, é possível fixar alguns pequenos jogos dentro das quadras de uma escola. Levandose em consideração uma turma de 24 alunos, a figura 3.1 mostra seis jogos de $2 \times 2$, ao passo que a figura 3.2 apresenta quatro jogos de $3 \times 3$. A demarcação da área do jogo pode ser facilmente realizada por uma fita adesiva para qualquer tipo de jogos de invasão.

O benefício que os jogos de posse de bola proporcionam é o das crianças não terem que se preocupar (corporalmente) com direções. Elas podem movimentar-se de forma livre, em seu espaço e contar o número de passes que a equipe realiza. Podem ocorrer os seguintes acontecimentos no ensino de jogos de posse de bola:

- alguns alunos podem ser relutantes em jogar contra outra equipe, até que eles possam observar os passes e o que acontece durante o jogo. Se este for o caso, o professor deve encorajá-los a participar e interceptar passes dos colegas;

- os alunos podem permanecer parados, esperando pela bola e deixando de marcar o jogador adversário. $\mathrm{O}$ professor deve encorajar esses jogadores a criar movimentação no espaço aberto;

- pode acontecer ainda alguma dificuldade em detrimento da aproximação de- 
masiada do colega com posse de bola, causando certa dificuldade no que se refere à movimentação no espaço, fazendo com que o jogo fique congestionado, diminuindo a probabilidade de passes completos e efetivos em razão da pobre utilização do espaço e do tempo. Faz-se necessário sugerir aos alunos, que eles poderão ter sucesso com seus companheiros movimentando-se e ocupando espaço. Talvez o aluno não entenda $o$ que deve ser feito e com isso possa se movimentar fora do alcance dos passes, de tal forma que o professor necessita, neste caso, demonstrar as distâncias apropriadas;

- freqüentemente o jogador de posse de bola leva um bom tempo para decidir a quem passar; isso pode causar frustração por parte da equipe desse jogador porque os defensores da outra equipe terão tempo suficiente para a sua movimentação e marcação. Lembre-se de que a velocidade de pensamento em um jogo é desenvolvida da mesma forma que as habilidades motoras. Somente realizando decisões em tais situações, as crianças desenvolvem aspectos cognitivos e motores. Ocasionalmente a reconstrução de situações de jogo, para demonstrar decisões apropriadas, pode ser uma estratégia de ensino eficaz;

- muitas vezes o jogador com a posse de bola fica descuidado; isso representa algum pensamento inteligente por parte dos iniciantes. É um reconhecimento que o jogador com bola não pode se movimentar com tanta facilidade (ou conforme as regras estabelecidas) e não será uma ameaça. $\mathrm{O}$ que veremos nesse caso é uma dupla dependência do outro jogador (dentro de um jogo 2x2). Isso torna o jogo difícil para a manutenção da posse de bola e a situação pode requerer algum tipo de intervenção por parte do professor. É preciso tentar o seguinte: requerer

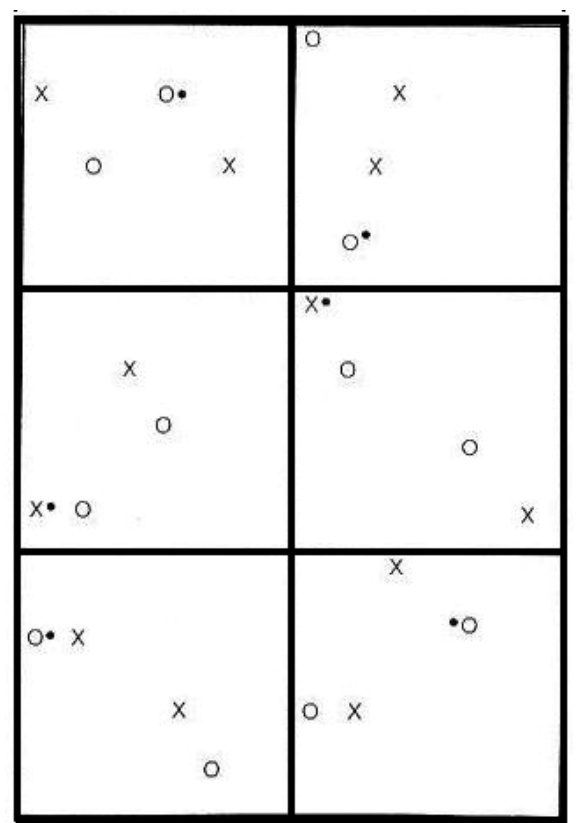

Figura 3.1 - Jogos de invasão 2x2 Fonte: Mitchell, Oslin e Griffin (1997).

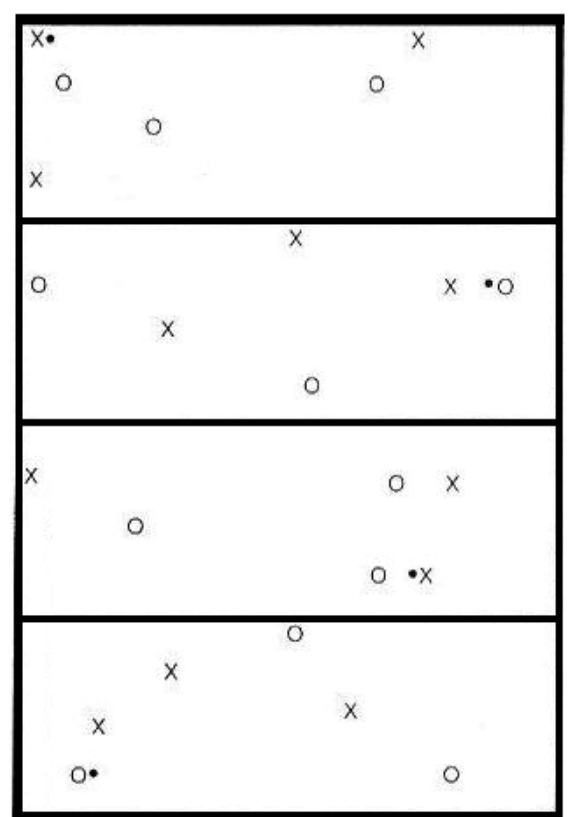

Figura 3.2 - Jogos de invasão $3 \times 3$ 
uma marcação individual, incentivar uma ampla movimentação do jogador que dá suporte, a fim de tornar o jogo mais dinâmico e permitir que o jogador com a posse consiga se movimentar, ou que pelo menos dê três passos;

- a bola certamente irá sair e o professor deve ensinar o início e o re-início de regras no jogo, nas saídas de bola.

A melhor maneira de complexificar os jogos de invasão, para os iniciantes, é o fixar de um objetivo, utilizando um par de cones em cada linha de fundo do campo ou quadra e explicar para ambas equipes onde estas devem arremessar/lançar a bola. Segue algumas preocupações:

- algumas crianças irão necessitar que a informação seja repetida pelo professor, sobre objetivo do jogo - onde ela deve pontuar;

- é melhor apenas restringir movimentos com a bola para evitar conflitos, do que impedir que os movimentos sejam feitos;

- insistir para que a bola seja chutada próximo do chão, a fim de não ultrapassar o nível do cone ou que o objetivo seja atingir o cone ou ainda contorná-lo sem derrubá-lo;

- ensinar o re-início das saídas de bola.

A largura do gol deve ser diminuída para que seja possível dispensar o goleiro. Este tamanho permite aos jogadores uma permanência ativa e um envolvimento nas tomadas de decisões do jogo. Assim que o jogo é aprimorado, é possível aumentar o tamanho do gol e incluir um goleiro. Um goleiro traz grandes mudanças para precisão dos chutes/arremessos e, acaba proporcionando a ambos os times uma estratégia de defesa e ataque, pois permite maior espaço aos jogadores dentro do jogo. Novamente, algumas sugestões: em primeiro lugar, a bola deve ser macia o suficiente para não machucar o goleiro; em segundo lugar, por razões de segurança, uma linha deve ser delimitada (defesa) para livre movimentação do goleiro - nenhum jogador deverá permanecer nesse espaço; e, em terceiro lugar, o goleiro deve ser alterado freqüentemente.

Os jogos de invasão necessitam que o ataque ultrapasse a defesa, progredindo em direção ao gol. Uma forma interessante de ensinar tal progressão é posicionar um jogador "alvo" na metade da quadra oposta e fazer com que a bola chegue a esse jogador através de passes. Esta é uma forma rápida de transição da defesa para o ataque. No futebol, esse jogador assume a posição de centro-avante, e no basquetebol, utilizamos o termo pivô. Sem levar em consideração a utilização do termo (iremos utilizar jogador "alvo"), a incorporação desse jogador em pequenos jogos é importante para o ensino de penetração no ataque, que requer a observação de espaços na equipe adversária para que os passes possam atingir o referido jogador "alvo". Dentro de um jogo 3x3 a equipe pontua quando a bola chega no jogador "alvo" da direita (JAd) ou da esquerda (JAe), como mostra a figura 3.3. Deve-se ficar atento para os seguintes pontos em jogos de jogador "alvo":

- os jogadores devem ser lembrados que o jogador "alvo" está no lugar do gol, que o propósito do jogo não é mais o arremesso ao gol, mas o passe para o jogador da própria equipe (jogador "alvo") que está posicionado atrás da linha de fundo da quadra ofensiva;

- jogadores "alvo" têm naturalmente uma tendência inicial de permanecer fixo, parado (que não ajudará seus companheiros atingirem o objetivo por meio dos passes) e irão precisar ser relembrados que eles podem se movimentar constantemente para auxiliar a equipe a encontrar espaços de forma que os outros jogadores possam passar;

- será importante enfatizar o re-início após a equipe pontuar, atingindo o jogador "alvo" (jogadores "alvo" devem devolver a bola para a outra equipe após a pontuação). 


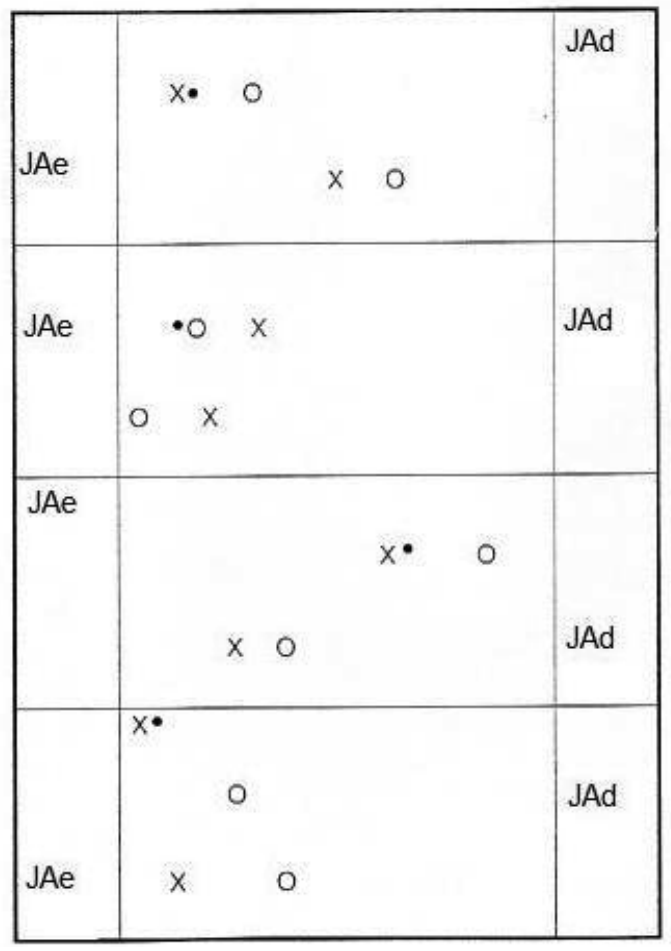

Figura 3.3 - Quadras ou campos (áreas) para jogos de invasão $3 \times 3$ com jogadores alvo. JAd - jogador alvo da direita e JAe - jogador alvo da esquerda estão posicionados nas respectivas zonas.

Fonte: Mitchell, Oslin e Griffin (1997).

\section{Considerações finais}

Com o propósito de repensar a prática pedagógica da Educação Física e, principalmente, do esporte escolar, buscamos apresentar algumas possibilidades de intervenção, tendo em vista as quatro categorias citadas, enfatizando a categoria jogos de invasão, no sentido de incrementar as práticas do handebol, voleibol, basquetebol e futebol. $\mathrm{O}$ ensino de esporte, nesta perspectiva, deve ser baseado na complexidade, criticidade, reflexão e análise.

Busca-se, ainda, apresentar algumas sugestões de intervenção pedagógica no ensino do esporte, como também demonstrar a importância de re-significação do espaço físico e de materiais com os quais a criança irá interagir.

É importante ressaltar que o ensino de esportes por meio de jogos não vai de encontro aos ditos jogos pré-desportivos, uma vez, que o objetivo da iniciação esportiva apresentado nesse texto é o de contribuir para uma educação pautada no desenvolvimento do aluno, da inteligência esportiva, da capacidade de tomada de decisão e resolução de problemas táticos, do pensamento tático, cujo foco é o aluno e não o esporte. Para tanto,

A formação da cidadania, da responsabilidade, da autonomia e da independência deve ser baseada nas atividades de estímuloà consciência crítica e inteligência nos jogos. Assim o papel do ensino deve ser (re)significado. Problemas simples são indicados às crianças menores e problemas de maior complexidade aos adolescentes e jovens. [...] Paralelamente ao ensino da leitura, da escrita, da matemática, a educação esportiva deve ocupar um lugar de destaque na formação da inteligência/ pensamento estratégico [...] também a busca por autonomia e desenvolvimento da inteligência, da capacidade de detectar e solucionar problemas deve ser um dos principais objetivos dos planejamentos e projetos pedagógicos (SADI, 2005, p. 5-6).

Sendo assim, cabe aos professores de educação física lançar mão do ensino de táticas nos jogos, dentro de uma vivência teórico-prática, almejando o nível de complexidade de cada série/idade escolar, tendo em vista o desenvolvimento da cognição/ compreensão.

Apesar das dificuldades encontradas na área, como por exemplo, a falta de recursos materiais e estruturas adequadas, ainda é possível re-significar o ensino do esporte que se encontra em patamar meramente técnico e recreativo. O ponto de partida da Pedagogia do Esporte deve caminhar no sentido do desenvolvimento significante/significativo para a vida do aluno. Nesta direção, o ensino do esporte, para além do ensino de técnicas e habilidades, deve instigar no aluno o 
porquê, para quê do fazer gestual e, ainda, quando e como resolver problemas táticos, ou seja, estimular a compreensão/cognição como ferramenta de intervenção no jogo. Faz-se necessário, portanto, a criatividade do professor frente às mudanças práticas das aulas, dos procedimentos do dia-a-dia dos alunos, bem como o desenvolvimento de novas perspectivas.

Teaching sports through games: developments and applications

\footnotetext{
Abstract

The development of Sport Pedagogy in Brazil is analyzed in this text in the light of the discussions on the teaching sports through games approach. The main reference is the work of Mitchell, Oslin and Griffin (2003). This research work presents pedagogical and methodological procedures related to invasion games and it offers perspectives for the work of physical education teachers.

Keywords: sports - pedagogy - physical education.

Enseñanza de deportes por medio de juegos: desarrollo y usos

\section{Resumen}

El desarrollo de la Pedagogía Deportiva en Brasil que se trata en este texto, empieza con la discusión de deportes de enseñanza a través de juegos. La referencia teórica utilizada es el enfoque americano (Mitchell, \& de Oslin; Griffin, 2003). Los procedimientos pedagógicos y metodológicos relativos a juegos de invasión y perpectivas de trabajo son presentados a los profesores de Educación Física.

Palabras-clave: deporte - pedagogía - educación física.
}

\section{Referências}

GARGANTA, J. (Re)fundar os conceitos de estratégia e táctica nos jogos desportivos colectivos, para promover uma eficácia superior. In: CONGRESSO DE CIENCIAS DO DESPORTO E EDUCAÇÃO FÍSICA DOS PAÍSES DE LÍNGUA PORTUGUESA, 11., 2006, São Paulo. Anais... Revista Brasileira de Educação Física, São Paulo, 2006.

MITCHELL, S.; OSLIN, J.; GRIFFIN, L. Teaching sport concepts and skills: a tactical games approach. Kent, Ohio: Human Kinetics, 1997.

. Sport fundations for elementary Physical Education: a tactical games approach. Kent, Ohio: Human Kinetics, 2003.

SADI, R. Educação Fisica, trabalho e profissão. Campinas, Komedi, 2005.

SCAGLIA, A. Os jogos/brincadeiras de bola com os pés e o futebol: o início de uma profícua história sistêmica/complexa. Revista Movimento E Percep̧̧ão, Pinhal - São Paulo, v. 5, n. 6, 2005.

Recebido: 28 de junho de 2007

Aprovado: 23 de outubro de 2007

Endereço para correspondência

renatoufg@gmail.com

janaina.cortes@gmail.com

torresbab@gmail.com 